\title{
Educação, "neodesenvolvimentismo" e Serviço Social: os IFs em questão
}

\author{
Education, "neo-developmentism" and Social \\ Work: the Federal Institutes (Fl's) in focus
}

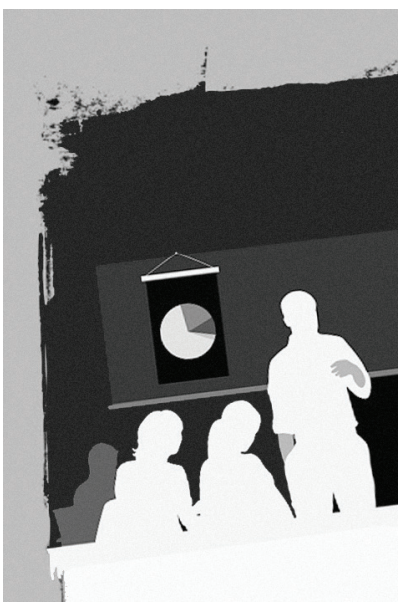

\author{
Evelyne Medeiros Pereira* \\ Denise de Araújo Silva Holanda** \\ Raí Vieira Soares*** \\ Samilly Elise de Souza Silva****
}

Resumo: Este texto tem como escopo analisar a experiência do curso de Serviço Social no Instituto Federal de Educação, Ciência e Tecnologia do Ceará (IFCE) em meio às transformações contemporâneas, particularmente da realidade brasileira, atentando para o debate em torno do "neodesenvolvimentismo" e suas inflexões no Serviço Social. A contradição entre acesso e precarização que caracteriza a educação superior hoje demanda refletir sobre os desafios postos para a formação profissional e a construção de estratégias coletivas que venham a garantir conquistas não apenas para a profissão, mas para o conjunto da classe trabalhadora.

Palavras-chave: Educação. Formação profissional. Serviço Social. Neodesenvolvimentismo. Institutos Federais (IFs).

* Professora do Instituto Federal de Educação, Ciência e Tecnologia do Ceará (IFCE), Fortaleza (CE), Brasil, líder e pesquisadora do Núcleo de Educação, Políticas Públicas e Serviço Social (NEPPSS/IFCE); doutoranda em Serviço Social na Universidade Federal do Rio de Janeiro (UFRJ).E-mail: evelyne.mp2913@ gmail.com.

** Bacharel em Serviço Social pelo IFCE; Fortaleza (CE), Brasil. E-mail: denisinhasilva@hotmail.com.

*** Estudante de Serviço Social do IFCE; Fortaleza (CE), Brasil, membro da Coordenação Regional da Executiva Nacional dos Estudantes de Serviço Social (Enesso) e do Núcleo de Educação, Políticas Públicas e Serviço Social (NEPPSS/IFCE).E-mail: raivieiracmpb@hotmail.com.

**** Estudante de Serviço Social do IFCE; Fortaleza/CE, Brasil, membro da Coordenação Regional da Enesso.E-mail: samillyelise@hotmail.com. 
Abstract: The aim of this article is to analyze the experience related to the graduation course of Social Work at Instituto Federal de Educação, Ciência e Tecnologia do Ceará (IFCE) — Federal Institute of Education. Science and Technology of Ceará (FICE) - amid contemporary changes, particularly in the Brazilian reality, focusing on the discussion about "neodevelopmentism" and its inflections in Social Work. The contradiction between access and precariousness - and such a contradiction characterizes the university education nowadays - requires thinking over the challenges raised about the professional formation and the construction of collective strategies to ensure conquests not only for the profession, but also for the set of the working class.

Keywords: Education. Professional formation. Social Work. Neo-developmentism. Federal Institutes (FI's).

\section{Introdução}

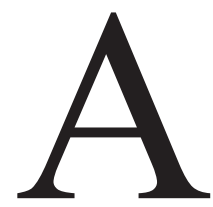

trajetória do Serviço Social no Brasil apresenta particularidades históricas que permitiram alcançar passos mais largos na sua legitimidade, em seu projeto e estatuto profissional. Todavia, a marca do conservadorismo ainda perdura tendo como expressão a dificuldade de romper com a "lógica do passado" que caracteriza a profissão no âmbito estrito da execução terminal das políticas sociais mediante uma formação técnica especializada voltada exclusivamente para a prática da assistência, pretensamente neutra, e manutenção do status quo. Esse processo, vale lembrar, não pode ser compreendido à parte de um conjunto de transformações que configuram a realidade contemporânea.

Nesse sentido, na última década, caracterizada pela ascensão de um modelo de desenvolvimento no país que, de um lado, aponta para a retomada do nível de intervenção estatal e dos índices de crescimento econômico e, de outro, revela o predomínio de tendências condizentes com o atual processo de reestruturação produtiva e financeirização do capital, vem se conformando um verdadeiro pêndulo entre acesso e precarização que passa a atravessar, entre outras, a política de educação superior. No âmbito do Serviço Social, esse processo implica diretamente a formação de profissionais com novas exigências e competências.

No estado do Ceará, conforme dados do Conselho Regional de Serviço Social (Cress), nos últimos seis anos ampliou-se em mais de 600\% o número de bacharéis em Serviço Social com registro profissional no Cress, advindos 
especialmente da esfera privada nas modalidades presencial e à distância (Cress, 2014). Se por um lado essa expansão passa a ser identificada como acesso ao ensino superior, por outro é acompanhada pelo adensamento dos diversos problemas na profissão, a exemplo do aligeiramento dos conteúdos e do rebaixamento acadêmico que tendencialmente implica um perfil profissional mais pragmático, apresentando profundas divergências com os princípios que orientam o projeto ético-político da profissão, fruto de um esforço coletivo que tem impulsionado o processo de "renovação da profissão" na "intenção de ruptura" (Netto, 2011) com o conservadorismo.

Em meio a tais circunstâncias, chamamos a atenção para a criação em 2010 do curso de Serviço Social no Instituto Federal de Educação, Ciência e Tecnologia do Ceará (IFCE), campus Iguatu, configurando-se como o primeiro curso da Rede Federal de Educação Profissional, Científica e Tecnológica no país, sendo o segundo presencial e público no Ceará. Essa experiência, apesar de inédita, nos oferece um conjunto de subsídios para melhor entendermos as tendências, contradições e desafios postos hoje para a educação superior e a formação profissional no Brasil no contexto do "neodesenvolvimentismo".

Vale destacar que o presente artigo é fruto de uma pesquisa realizada a partir do Programa Institucional de Bolsas de Iniciação Científica (Pibic) do IFCE entre 2012 e 2013, sendo o texto final redigido no primeiro semestre de 2014. Como metodologia, foi priorizada a pesquisa bibliográfica, a análise documental, a observação de campo, além da realização de entrevistas e questionários junto aos estudantes, docentes, gestores e entidades representativas da profissão, respeitando os parâmetros éticos da pesquisa com seres humanos, conforme Resolução n. 466/2012. Esse caminho nos permitiu analisar o processo de implantação do curso em questão sem perder de vista a compreensão da totalidade social.

\section{A política educacional no Brasil e suas inflexões sobre o Serviço Social}

A educação no Brasil é atravessada por uma formação sócio-histórica peculiar pautada na dinâmica da "modernização conservadora" (Fernandes, 2006) e marcada por "arranjos de cúpula, de cima para baixo" (Ianni, 2004, 
p. 231). Esse lastro é central na conformação do capitalismo brasileiro e de suas classes fundamentais. A burguesia no Brasil vem assumindo, em sua natureza, o caráter de dependência ao capital estrangeiro, consolidando-se no poder fundamentalmente pela combinação de práticas paternalistas e repressoras. É, portanto, sob essa marca que a educação no país tem se desenvolvido.

No caso específico do ensino superior, a instituição, por excelência, criada para tal finalidade foi a universidade, que surge no Brasil tardiamente em relação a outros países da América Latina, como uma demanda da elite no país. Assim, o processo de constituição da educação pública como um direito foi e ainda é atravessado por conflitos de classes pautados, de um lado, pela reconstrução de estratégias de segregação e, mais recentemente, de privatização e mercantilização; de outro, pela possibilidade de democratização efetiva da educação pública brasileira, tão presente, por exemplo, enquanto bandeira histórica de reivindicação do movimento estudantil pela Reforma Universitária.

É sob essa tensão, influenciada pela dinâmica mundial, que, especialmente a partir dos anos 1990, a educação vira uma peça importante do circuito neoliberal em meio a um processo de contrarreforma do Estado (Behring, 2008) guiado por um "intenso programa de ajuste estrutural, privatizações e alta concentração de renda" (Gentili e Oliveira, 2013, p. 254), pela manutenção das altas taxas de juros e pela reestruturação produtiva com a ascensão de novas modalidades de subemprego, polivalência, intensificação da dupla jornada de trabalho das mulheres, utilização de mão de obra infantil, migrante e, até mesmo, o aumento de condições de ocupações análogas ao trabalho escravo (Antunes, 2003).

Nesse contexto, a intensa expansão privada e aligeirada (presencial e à distância/EaD), a precarização e o sucateamento do ensino público, sendo condicionado ao "produtivismo acadêmico" e a parceria público-privada, além das dificuldades relativas à garantia do tripé ensino, pesquisa e extensão e a política de assistência estudantil são aspectos que constituem a realidade da educação pública superior.

A introdução da EaD, respaldada na Lei de Diretrizes e Bases (LDB), de acordo com Lima (2008), se configura como uma falsa ideia de democratização da educação superior sob a aparência de uma política de educação "inclusiva" que garante, de forma mínima, o acesso de uma parcela pauperizada de países periféricos, como o Brasil, a educação superior. Nessa modalidade, os cursos das 
Ciências Humanas passam a ser os mais visados, pois estes supostamente não demandariam maiores investimentos. Ainda sobre isso, Dahmer (2008) destaca que na modalidade $\mathrm{EaD}$ o professor transforma-se em "tutor", impossibilitando a relação professor-aluno e discussões relevantes no processo formativo, além de impedir ao estudante desenvolver experiências acadêmicas e políticas, suscitando maior criticidade e ampliação da "visão de mundo" (Gramsci, 2007).

Essa lógica atinge contundentemente a formação profissional em Serviço Social fundamentada no "rigoroso trato teórico, histórico e metodológico da realidade social", na "adoção de uma teoria social crítica que possibilite a apreensão da totalidade social" e inviabilize a fragmentação de conteúdos, na articulação entre as dimensões investigativa e interventiva, na indissociabilidade tanto entre as dimensões de ensino, pesquisa e extensão como entre o estágio e a supervisão acadêmica e profissional (Abepss, 1996). Tais parâmetros conjugados ao exercício de uma deontologia respaldada em condutas e em valores sociais, como liberdade, democracia, cidadania, igualdade, justiça social e respeito à diversidade, com garantias do resguardo e cumprimento dos direitos individuais e sociais, na prática junto as instituições ou na relação com o usuário, contrasta com as reconfigurações do Estado, dos processos de trabalho e do padrão "ideológico-científico" vigente que exigem cada vez mais um profissional estéreo de projetos coletivos.

Esse cenário, porém, apresenta novas configurações, especialmente na última década, o que tem diferenciado, em certa medida, o atual período em relação aos anos 1990.

\subsection{0 "neodesenvolvimentismo" e a formação profissional em Serviço Social}

Para alguns autores, como Boito Jr. (2012), os últimos dez anos são caracterizados pela conformação de um governo de "composição de classes", caracteri-

1. Segundo Harvey (2010, p. 19), "há algum tipo de relação necessária entre a ascensão de formas culturais pós-modernas, a emergência de modos mais flexíveis de acumulação do capital e um novo ciclo de 'compressão do tempo-espaço' na organização do capitalismo [...]. A fragmentação, a indeterminação e a intensa desconfiança de todos os discursos universais são um marco do pensamento pós-moderno". 
zado por uma ampla aliança dirigida pela burguesia interna, ${ }^{2}$ muito embora seja policlassista, ou seja, envolva também alguns segmentos de trabalhadores. Contudo, todo esse processo não pode ser compreendido sem a decisiva interferência das relações internacionais sobre a política interna. Estaríamos falando, portanto, de uma política de desenvolvimento possível nos marcos da hegemonia neoliberal. Isso tendo em vista as diferenças significativas entre o "desenvolvimentismo" do período de 1930 a 1980 e o "neodesenvolvimestismo" atual. Neste, o crescimento é bem mais modesto, embora consideravelmente maior do que o verificado na década de 1990, além da menor capacidade distributiva da renda (Boito Jr., 2012, p. 6).

Ainda segundo o autor, as frações de trabalhadores que compõem essa frente, parte do segmento mais precarizado no mundo do trabalho, localizado principalmente nas periferias dos grandes centros urbanos do país, são atraídas passivamente, desorganizadamente e de forma despolitizada pelas políticas de transferência de renda. Assim, a acentuada atenção dada a essas ações, somada à falta de investimento em políticas mais estruturantes, imprimindo um teor liberalizante a algumas, a exemplo da saúde, dos aeroportos e, mais recentemente, dos portos, são outras características da atual conjuntura brasileira. Contraditoriamente, todo esse processo, em especial a partir da implementação da Política Nacional de Assistência Social (PNAS) e do Sistema Único da Assistência Social (Suas), em 2004, vem demandando um amplo e diversificado mercado de trabalho para assistentes sociais, além de consolidar os serviços de assistência social como uma política, fato este que contribuiu decisivamente para a ampliação dos cursos superiores de Serviço Social e dos desafios que a profissão passa a enfrentar nos últimos anos.

Além disso, a recomposição da classe trabalhadora com a ascensão de um ciclo econômico de redução de desemprego e da extrema pobreza, ${ }^{3}$ além da

2. "A grande burguesia interna encontra-se distribuída por diversos setores da economia — mineração, construção, agronegócio, a indústria de transformação e, em certa medida, os grandes bancos privados e estatais de capital predominantemente nacional. O que unifica essas grandes empresas é a reivindicação de favorecimento e de proteção do Estado na concorrência que elas empreendem com o capital estrangeiro [...]. Um fato importante nessa área foi [...] o fortalecimento do Mercosul" (Boito Jr., 2012, p. 7-8).

3. Conforme o Ministério do Desenvolvimento Social (MDS), "o governo federal alcança uma marca histórica: a retirada de 22 milhões de brasileiros da extrema pobreza, do ponto de vista da renda, nos últimos dois anos". Disponível em: <www.mds.gov.br>. Acesso em: 3 mar. 2013. 
abertura de novos concursos; a inserção de jovens, na maioria das vezes de forma precarizada, no mundo do trabalho e na educação superior, constituindo um "novo" segmento social denominado por Ruy Braga (2012) de "precariado"; a debilidade de servições públicos como saúde e transporte coletivo, somado ao congelamento salarial de setores médios da classe trabalhadora, à conturbada vida urbana nos grandes centros e ao acirramento das contradições da "frente neodesenvolvimentista" (Boito Jr., 2012), um cenário de lutas, manifestações e greves caracterizam a realidade mais recente do país. Esses sujeitos, para Alves (2013), apresentam os limites radicais do projeto de desenvolvimento em curso, em processo de esgotamento, incapaz de dar resposta às necessidades sociais dos trabalhadores, razão pela qual as reformas estruturais continuam sem avanço, tais como as reformas agrária, urbana e política.

No âmbito da educação superior, Gentili e Oliveira (2013) apresentam alguns aspectos que compõem o "balanço do quadro geral" das políticas educacionais desenvolvidas na última década, como: a considerável ampliação das matrículas no ensino público e privado a partir dos programas Universidade para Todos (ProUni) e o de apoio a planos de Reestruturação e Expansão das Universidades Federais (ReUni); a criação da Rede Federal de Educação Profissional, Científica e Tecnológica juntamente aos Institutos Federais de Educação, Ciência e Tecnologia (IFs); a consolidação e ampliação do Fundo de Financiamento Estudantil (Fies); a implantação das cotas sociais e raciais nas Instituições de Ensino Superior (IES) federais; a consolidação do Exame Nacional do Ensino Médio (Enem) em substituição do vestibular, além da grande abertura de cursos de graduação à distância.

Conforme análise dos dados mais recentes do Instituto Nacional de Estudos e Pesquisas Educacionais Anísio Teixeira/Inep (2010), em relação ao ensino superior, ocorreu um aumento exponencial do número de matrículas em todas as redes e modalidades (presencial e à distância). No sistema público (federal, estadual e municipal) passamos de 251.239 matrículas em 2001 para 475.884 em 2010. Um aumento de 89,4\% das vagas. Já a proporção para a rede privada sofre um aumento ainda mais elevado. De 792.069 matrículas em 2001 chegamos a 1.706.345 em 2010. Um aumento de 115,4\% das vagas. Portanto, o total de números de matrículas em todas as redes mais que duplicou nesse período de dez anos. Vale ressaltar que a expansão do número de matrículas 
também foi acompanhada por um aumento do número de docentes nas IES que, no entanto, não supre a carência em toda a rede de ensino. ${ }^{4}$.

Em 2010, havia 2.378 IES, das quais 88,3\% são privadas e 11,7\% públicas, sendo $4,5 \%$ estaduais, $4,2 \%$ federais e $3 \%$ municipais. Registra-se, também, que as maiores concentrações de matrícula por instituição estão nas categorias federal e estadual. Além disso, observando-se a organização acadêmica, a maior parte das matrículas continua concentrada nas universidades $(54,3 \%)$. No que se refere ao número de IES por organização acadêmica, predominam as faculdades $(85,2 \%$ das IES).

Ainda sobre a expansão da educação superior, vale destacar um aspecto que, apesar de mais recente, vem cumprindo um papel central nesse processo: a instituição da Rede Federal de Educação Profissional, Científica e Tecnológica junto à criação dos IFs, que passam a ter também como objetivo e finalidade a educação superior em várias áreas, como também pós-graduação lato sensu e sricto sensu, embora com ênfase na formação tecnológica (Brasil, 2008). Sobre isso, em termos de expansão de universidades federais, de 2002 a 2010 foram criados 126 novos campi, totalizando 274 em 230 municípios. Isso com a perspectiva de até 2014 obter um total de 321 campi em 275 municípios. Já em relação aos IFs, observa-se que de 2002 a 2010 foram criados 214 campi em 201 novos municípios antes não atendidos, totalizando 354 campi. A previsão do governo federal é que até 2014 sejam 562 campi em 512 municípios, ou seja, 241 campi a mais que o previsto para as universidades (MEC, 2013).

Diante desse contexto, houve uma relativa reconfiguração do perfil de estudante, mesmo que persista um déficit histórico longe de ser correspondido pelas atuais iniciativas na política educacional. A condição de "estudante-trabalhador" tem sido cada vez mais comum, o que põe desafios enormes ao modelo de educação superior ainda vigente. Isso diante de um público com tempo muitas vezes escasso para participar de qualquer outra atividade acadêmica além do ensino, sendo um aspecto relevante para a qualidade na formação.

4. “[...] enquanto o número de vagas ofertadas pelas universidades federais cresceu $111 \%$ entre 2003 e 2011, a quantidade de novos professores cresceu apenas 44\% até 2012 [...]. A relação aluno-professor passou de 1/15 para 1/28". Disponível em: <portal.andes.org.br/imprensa/documentos/imp-doc-1904651914.pdf>. Acesso em: 12 maio 2013. 
Por outro lado, é certo que, mesmo sob circunstâncias adversas, possibilitar a vivência universitária - e, quem sabe, político-organizativa através do movimento estudantil, - a uma camada da população que antes não tinha acesso à educação superior é, sem dúvida, um fator ímpar que, inclusive, poderá influenciar, a partir de suas insatisfações, no alcance de maiores conquistas no campo da educação pública aos trabalhadores. Isso tendo em vista que, em muitos casos, trata-se da primeira geração familiar a ter formação superior. Essa relação também pode ser feita do ponto de vista dos trabalhadores da educação que passam a se deparar com a tão sonhada estabilidade, mas em circunstâncias muitas vezes precárias, demandando, por parte do sindicalismo brasileiro, novos mecanismos de organização e luta política.

A chegada de instituições públicas de ensino superior, uma realidade ainda recente em muitas localidades, é, também, um fator que merece atenção, especialmente diante da histórica desigualdade regional que caracteriza o país. Isso tendo em vista que, com todas as dificuldades encontradas em termos de infraestrutura e qualidade em geral, a interiorização dessas instituições é acompanhada por um processo mais amplo caracterizado por um conjunto de fatores, como: formação das "cidades médias", reorganização territorial da economia através dos Arranjos Produtivos Locais (APLs) e da criação de polos industriais, mudanças nos fluxos migratórios, descentralização dos serviços, entre outros. Sobre isso, vale observar a criação de algumas universidades federais nas cidades do interior do Nordeste brasileiro, como: Universidade de Integração Internacional da Lusofonia Afro-Brasileira (Unilab), Universidade Federal da Região do Cariri (UFCA), Universidade Federal do Oeste da Bahia (Ufoba) e Universidade Federal do Sul da Bahia (Ufesba).

Outro importante aspecto a ser considerado é a formação de uma massa de jovens recém-graduados em determinadas áreas onde tem sido mais viável a expansão, almejando uma ascensão social com base em uma carreira profissional promissora, mas com uma inserção precária nas relações de trabalho e na vida social.

No caso do Serviço Social, podemos relacionar ao fenômeno caracterizado por Iamamoto (2009) como "exército assistencial de reserva”. Para entender tal processo, é preciso lembrar alguns aspectos centrais que caracterizam a trajetória da formação de assistentes sociais no Brasil na "perspectiva histórico- 
-crítica" (Montaño, 2009), como: a inscrição da formação no âmbito universitário, o avanço da produção de conhecimentos e pesquisa junto à expansão da pós-graduação, a interlocução com a teoria social crítica, novas demandas e competências no âmbito das políticas sociais, as revisões curriculares e a aprovação das Diretrizes Curriculares da Abepss (1996) em sintonia com os princípios e disposições gerais do Código de Ética Profissional (1993). Além disso, o estágio supervisionado passa a constituir-se como central para o aprendizado teórico-prático do trabalho profissional, devendo corresponder à carga horária mínima de $15 \%$ do curso. Vale destacar a construção da Política Nacional de Estágio (PNE) da Abepss (2008), que passa a dar mais subsídios para as IES regulamentarem e supervisionarem o estágio em Serviço Social.

Dessa forma, diante do atual quadro em que se apresenta a política de expansão da educação superior, especialmente via ensino privado e à distância, existem várias dificuldades e impasses postos para a formação profissional, tal como expressa os documentos das entidades do Serviço Social (Abepss, 2008). Em relação à realidade cearense, segundo dados do Cress/CE (2014), o estado possui hoje 24 instituições que oferecem cursos de Serviço Social. Destas, somente a Universidade Estadual do Ceará (Uece) e o IFCE ofertam cursos públicos, presenciais e gratuitos; os demais são implementados pela iniciativa privada, muitos na modalidade à distância, e criados a partir de 2005 em mais de vinte cidades do interior do Ceará. Diante desse quadro, o número de assistentes sociais inscritos no Cress quase dobrou nos últimos seis anos. Em 2013, a quantidade de profissionais formados no estado pela $\mathrm{EaD}$ era de $45,5 \%$; já aqueles formados pelo ensino privado presencial correspondiam a 40,9\%, sendo apenas $11,2 \%$ dos inscritos advindos do ensino público presencial, pela Uece.

Iamamoto (2007) alerta sobre as consequências da expansão desordenada, aligeirada e precarizada de cursos de Serviço Social, distante de uma relação com os parâmetros nacionais de qualidade, mesmo sob a avaliação do MEC em uma lógica questionável de ranqueamento dos cursos, podendo intensificar os seguintes aspectos: rebaixamento salarial, precarização e insegurança no trabalho; despolitização da categoria, dificultando a sua organização; inexistência de vivências estudantis, o que poderá comprometer decisivamente a direção social do projeto profissional. Tal realidade vem fomentando por parte da categoria a discussão acerca de uma suposta "crise do projeto ético-político profissional". 


\section{Os IFs, a realidade cearense e o curso de Serviço Social}

A expansão e interiorização da educação superior nos últimos dez anos toma materialidade no Ceará especialmente através das universidades, faculdades e, mais recentemente, dos IFs, o que vem corroborando para a referência do estado no âmbito da expansão da Rede Federal de Educação Profissional, Científica e Tecnológica, por meio do IFCE — mediante integração dos Centros Federais de Educação Tecnológica do Ceará (Cefets) e das Escolas Agrotécnicas Federais (EAFs). Em termos numéricos, até 2014 o planejamento é para 29 campi do IFCE, quando até 2002 existiam apenas cinco (MEC, 2014). Com esses números, a expansão da Rede no estado é considerada a maior do Brasil.

Nesse cenário, o IFCE, presente em todas as regiões do Ceará, oferece cursos superiores tecnológicos, licenciaturas, bacharelados, além de pós-graduações Entretanto, a expansão no interior é acompanhada também por um conjunto de impasses de várias ordens, desde a falta de infraestrutura física e recursos de gestão a dificuldade de contratação de um número suficiente de professores para suprir a demanda através de concurso público, implicando as condições de trabalho docente. Para entender melhor o papel que o IFCE vem tendo no estado em termos de educação superior, é importante destacar, entre outros aspectos, os seguintes:

Primeiro, trata-se de uma instituição com histórico voltado para formação, qualificação e especialização técnica e tecnológica de trabalhadores, marcado por mudanças que vão desde a criação da Escola de Aprendizes e Artífices e do Liceu Industrial do Ceará, na primeira metade do século XX, até a constituição das Escolas Técnicas e Agrotécnicas e, posteriormente, dos Cefets na década de 1990. Essas mudanças são concebidas, em geral, nos depoimentos dos gestores do IFCE, como um processo contraditório que, de um lado, amplia as possibilidades e sinaliza avanços no âmbito da oferta e diversificação de cursos (inclusive das áreas das ciências humanas), viabiliza maior captação de recursos, além de uma ampliação da autonomia institucional; por outro lado, por uma dificuldade de adesão especialmente por parte das instituições que deixaram de existir e passaram a congregar o IFCE, o que promoveu um verdadeiro "choque" de comportamentos, valores, concepções entre os servidores antigos e novos, 
em decorrência de uma "identidade institucional" ainda não consolidada. Assim, é uma instituição

que tem uma vocação bem maior daquilo que ela foi criada [...] a gente já tem o tripé próprio da universidade, os institutos também se apropriaram do ensino, da pesquisa e da extensão [...] e eu acredito que isso melhorou muito em termos da questão técnica, que era muito tecnicista [sic] as escolas profissionais, as antigas agrotécnicas, os Cefets, e hoje com essa roupagem de instituto avançou muito na questão também de formar as pessoas com uma visão mais critica. (Entrevistado 3)

O segundo aspecto importante sobre o IFCE, assim como os outros IFs, é a sua atual natureza jurídica de autarquia, detentora de autonomia "administrativa, patrimonial, financeira, didático-pedagógica e disciplinar” (Brasil, 2008). Nesse sentido,

a maior característica de criação dos institutos é a autonomia de abrir e fechar cursos inclusive de graduação e pós-graduação lato e stricto sensu [...] eu vejo que essa instituição ainda está precisando consolidar uma nova identidade [...] pelo menos está no discurso, devemos tentar nos tornar uma universidade tecnológica. (Entrevistado 1)

O terceiro aspecto é a relação entre ensino, pesquisa e extensão, de natureza pública e gratuita, que, no decorrer das mudanças que houve na Rede, passa a se configurar como um pilar nos IFs. Tal aspecto é acompanhado por uma política continuada de qualificação de servidores, prevista em Lei Federal n. 8.112/1990. Dessa forma, os IFs equiparam-se às universidades federais “em termos de funcionamento, de fomento à pesquisa e da prática de ações de extensão [...] foram também dotados de autonomia para gerenciar orçamento de custeio, alterar oferta de cursos, registrar diplomas e certificar competências profissionais". 5

Em meio a tais circunstâncias, o curso de bacharelado em Serviço Social do IFCE, campus Iguatu, é criado em 2010, apresentando-se, a priori, como

5. Disponível em: <http://ifce.edu.br/instituicao/sobre-nos.html>. Acesso em: 12 dez. 2013. 
uma excepcionalidade no país. Trata-se de um curso presencial, público e gratuito que possui duração de quatro anos, com oito semestres letivos, ${ }^{6}$ sendo o segundo curso presencial público do Ceará, após a graduação oferecida pela UECE há mais de sessenta anos.

A graduação possui em seu quadro docente na área de Serviço Social um total de quatro professoras efetivas e quatro docentes na condição de substituto ou temporário, ${ }^{7}$ além dos professores das áreas afins (Filosofia, Psicologia, Sociologia etc.). Em relação à formação acadêmica, os docentes, em geral, fizeram graduação e pós-graduação em instituições públicas. Chamamos a atenção para o considerável número de docentes da área específica em doutoramento (três professoras, sendo duas oficialmente afastadas) e com o título de mestre (quatro efetivas e uma substituta).

Levando em conta a condição de professor do Ensino Básico, Técnico e Tecnológico (EBTT) e a verticalização do ensino (Brasil, 2008), os docentes dos IFs em geral perpassam outros níveis de ensino (integrado, subsequente e/ ou superior), especialmente os das áreas afins. Esse aspecto foi, inclusive, conforme documentos internos, uma das principais motivações de contestação das docentes da área de Serviço Social junto a gestão do IFCE. ${ }^{8}$

Já com relação aos estudantes, que, em suma, ingressaram no curso por intermédio do Enem e são advindos de escolas públicas, possuem o seguinte

6. O curso oferta, semestralmente, 35 vagas e incorpora, em média, outros 10 alunos por transferência externa e/ou interna e cinco por admissão de graduados. Atualmente, a graduação estipula 3 mil horas de disciplinas, sendo 2.840 horas de disciplinas obrigatórias e 160 de disciplinas eletivas. Isso além das 450 horas de estágio supervisionado e 160 horas de atividades complementares (IFCE, 2013).

7. Tal quadro está passível a mudanças em curto prazo, tendo em vista o concurso público em vigência para três vagas de docentes efetivos na área de Serviço Social com a previsão de serem convocados até 2015 o total de quatro docentes divididos em duas subáreas: Fundamentos do Serviço Social e Política Social e Sociedade. Disponível em: <http:/qselecao.ifce.edu.br/concurso.aspx?cod_concurso=2510 >. Acesso em: 2 maio 2014.

8. Torna-se necessário acrescentar que, em muitos casos, a condição de docente EBTT, abre margem para que docentes de áreas específicas lecionem disciplinas de áreas afins, o que, somado algumas vezes à falta de recursos humanos suficientes para suprir a demanda existente, torna mais suscetível as condições de trabalho à precarização e a polivalência. Isso além da construção de "arranjos temporários", devidamente regulamentados, para suprir as necessidades mais imediatas, como a condição de "colaborador eventual" ou de "professor voluntário". Sobre o Plano de Cargos e Carreiras do Magistério EBTT, ver a Lei n. 12.772, de $28 / 12 / 2012$. 
perfil: faixa etária de 18 a 24 anos; majoritariamente mulheres, refletindo o traço histórico da profissão; apoiam ou participam do movimento estudantil ${ }^{9}$ e/ou de outros movimentos sociais de juventude, como o Levante Popular da Juventude; ${ }^{10}$ em torno de $40 \%$ são provenientes de outras cidades menores e, em geral, da zona rural, muito embora também haja a atração de estudantes de cidades maiores e até da capital do estado, daí a alta demanda por ações no âmbito da política de assistência estudantil; cerca de $16 \%$ estão inseridos em programas sociais, dentre os quais o Bolsa Família; a maioria trabalha e/ou possui algum tipo de renda mensal familiar, sendo de um a dois salários mínimos, o que implica tanto a grande procura de cursos superiores noturnos como na dificuldade que muitos apresentam em acompanhar os conteúdos; cerca de $26 \%$ participam de ações vinculadas a pesquisa, extensão e de apoio ao ensino; há um alto índice de envolvimento nas ações do curso ou mesmo em outras instituições (eventos, encontros, reuniões), inclusive com recursos muitas vezes subsidiados pela instituição.

Diante dessa realidade, o curso em questão vem se conformando e ganhando notoriedade por seu caráter público e gratuito, além de ser uma clara expressão das recentes transformações dos IFs. Isso, entretanto, não isentou o processo de abertura e consolidação da graduação de uma série de impasses, tensões e dificuldades que vão desde o confronto de ideias sobre formação e gestão educacional até a insuficiência de recursos humanos e infraestrutura adequada. Tais condições tomam maior proporção diante da condição inédita do bacharelado nos IFs.

Contudo, é possível observar por parte dos entrevistados em geral uma percepção otimista sobre o curso que, inclusive, passou por uma profunda reformulação curricular iniciada em 2012 e finalizada em 2013. ${ }^{11}$ A graduação é

9. Sobre esse assunto, sinalizamos a repercussão política da mobilização estudantil em 2014. Disponível em: $<$ http://www.cress-ce.org.br/noticias/informes/nota-de-apoio- $\% \mathrm{C} 3 \% \mathrm{~A} 0$-paraliza $\% \mathrm{C} 3 \% \mathrm{~A} 7 \% \mathrm{C} 3 \%$ A3o-dosas-estudantes-de-servi\%C3\%A7o-social-do-ifce $>$ e $<$ http://executivamess.wordpress.com/ 2014/01/22/nota-de-apoio-da-enesso-a-paralisacao-dxs-estudantes-de-servico-social-do-ifce-iguatu/>. Acesso em: 8 maio 2014.

10. Disponível em: <http://levante.org.br/>. Acesso em: 2 mar. 2014.

11. Nesse processo merece destaque o fortalecimento das instâncias coletivas (Colegiados, Coordenação do Curso, Núcleo Docente Estruturante/NDE) e a reconfiguração da organização curricular e dos conteúdos 
associada, por parte da gestão, a uma forma de a instituição "dialogar" melhor com a comunidade, fazendo cumprir a "função social"; ao desenvolvimento de uma postura crítica na formação; a um grande diferencial em relação aos demais cursos ofertados no IFCE, em especial no interior do estado; e, consequentemente, a muitos desafios. Por outro lado, é possível observar a vigência, pelo menos inicialmente, de um "senso comum institucional" pautado no "desenvolvimento social" e "empreendedorismo", reflexo do que ainda predomina na sociedade como um todo e tem o reforço dos discursos e ideologias de desresponsabilização do Estado e culpabilização do indivíduos por questões de ordem estrutural, favorecendo a "refilantropização" (Iamamoto, 2004) e a "assistencialização da seguridade social" (Mota, 1995). Essa lógica atravessa, em geral, as instituições como um todo e repõe no cotidiano profissional ameaças que implicam a "imagem social" (Ortiz, 2010) do Serviço Social que tendem a associar o profissional a um "agente da assistência, do desenvolvimento e da inclusão social", em vez de fortalecer a perspectiva dos direitos sociais.

Outro aspecto presente nos depoimentos é a referência feita a uma suposta incompatibilidade entre o perfil dos alunos e professores do curso com a estrutura organizativa da instituição, já que o Serviço Social possui uma direção voltada para um perfil questionador, de reivindicação e luta por direitos, desde a formação ao exercício profissional. Nesse sentido, seria um diferencial em relação ao perfil dos cursos predominantemente ofertados no IFCE de cunho tecnológico. Tal concepção, ao mesmo tempo, se contradiz quando aponta para uma "lógica institucional" passível de mudanças, não engessada, que tende a trabalhar com uma perspectiva mais ampla do que se possa entender por "tecnologia". Sobre isso, basta atentarmos para a história recente dos IFs e das modificações já ocorridas na "cultura institucional" que, hoje, é pautada por princípios como o "compromisso com a justiça social, equidade, cidadania, ética, [...] transparência e gestão democrática [...] natureza pública e gratuita do ensino" (IFCE, 2008). Tais princípios, inclusive, muito se aproximam daqueles considerados fundamentais no Código de Ética do/a Assistentes Social (Brasil, 1993). Cabe ressaltar mais uma vez que esses impasses, pautados por uma

das disciplinas, atentando para a flexibilização do currículo, articulação da teoria com a realidade, interdisciplinaridade, pluralismo e ética na profissional. 
relação aparentemente paradoxal entre a "lógica institucional" e o "projeto profissional do Serviço Social" não estão presentes apenas nos IFs, mas nas instituições como um todo, revelando um conjunto de contradições que permeiam as relações sociais, expressas no constante embate de ideias, projetos de formação e de sociedade.

Levando em consideração tais ponderações, observamos também que o curso de Serviço Social no IFCE tem sido associado a mudanças na dinâmica institucional. Para muitos, o curso vem demandando modificações e poderá contribuir nos processos que dizem respeito à gestão coletiva e democratização interna, com o fortalecimento dos colegiados, além da construção de novos parâmetros de formação, de pesquisa e extensão. Sobre isto, a graduação vem se destacando no desenvolvimento de atividades interdisciplinares de apoio ao ensino (a exemplo da monitoria acadêmica e dos grupos de estudos), pesquisa e extensão junto à gestão pública municipal e aos movimentos sociais que viabilizaram a criação e certificação do Núcleo de Educação, Políticas Públicas e Serviço Social (Neppss). Já quanto ao estágio supervisionado, as ações para sua implementação tiveram início no primeiro semestre de 2013, o que requer a construção da Política de Estágio Supervisionado em Serviço Social do IFCE, com referência na PNE da Abepss (2008), que ainda requer algumas mudanças inclusive no organograma da instituição, a exemplo da criação da Coordenação de Estágio Supervisionado em Serviço Social.

Outro fator importante a ser considerado na nossa análise é o alto nível de participação e envolvimento dos estudantes e professores do curso, expresso por meio de alguns aspectos, como: a criação, em 2011, do Centro Acadêmico de Serviço Social (Cass); a organização e realização das Semanas de Serviço Social do IFCE, que já está na sua quarta edição; a participação em importantes iniciativas da categoria estudantil e profissional, como os Encontros Nacionais e Regionais de Estudantes de Serviço Social (Eress/Eness), o Encontro Nacional de Pesquisadores em Serviço Social (Enpess), o Congresso Brasileiro de Assistentes Sociais (CBAS), as Oficinas Regionais e Nacionais da Abepss, o Projeto Abepss Itinerante, entre outros; a realização, nas dependências do IFCE, do Conselho Regional de Entidades Estudantis de Serviço Social (Coress), em 2012, e do Seminário Regional de Formação Profissional e Movimento Estudantil em Serviço Social (SRFPMESS), em 2014; a participação direta de 
estudantes na atual representação regional da Executiva Nacional de Estudantes de Serviço Social (Enesso), bem como a inserção de uma das professoras do curso na diretoria do Cress- $3^{\text {a }}$ Região.

A realidade demonstra um reconhecimento progressivo do curso, que já é um dos mais procurados no IFCE, ${ }^{12}$ com a perspectiva de ser avaliado pelo MEC em 2014, além de condições favoráveis à captação de recursos públicos através de incentivo à participação em eventos acadêmicos de docentes e discentes e o fomento à pesquisa, extensão e atividades de apoio ao ensino. Esse aspecto é central no processo de atração e formação de profissionais qualificados, especialmente diante de um cenário tão adverso para a garantia dos parâmetros de formação em Serviço Social.

A pesquisa nos possibilitou também compreender o atual Projeto Político-Pedagógico do Curso (PPC) como expressão do esforço e compromisso coletivo de servidores e estudantes na busca da consolidação e legitimação do curso na instituição em consonância com as Diretrizes da Abepss, levando em conta as particularidades tanto regionais como institucionais.

Diante dessa realidade, mediante um diálogo junto às representações da categoria (Abepss, Enesso, CFESS e Cress), observamos que, em geral, muito em virtude do desconhecimento ou mesmo da condição inédita da experiência no IFCE, predomina nos depoimentos a ponderação, de um lado, sobre o receio da expansão do curso de Serviço Social via IFs, tendo em vista o perfil histórico da instituição e sua possível incompatibilidade com a formação de assistentes sociais; de outro, a demonstração de interesse pelo tema e otimismo pelo fato de ser uma formação pública e gratuita, o que abre um leque de possibilidades frente à falta de conquistas maiores e efetivas em relação aos problemas enfrentados hoje na profissão.

O curso de Serviço Social no IFCE representou uma conquista muito importante da profissão no Ceará [...] para a classe trabalhadora, ao garantir um curso público, gratuito, e que a gente espera que seja de qualidade [...] no nosso planejamento estratégico está como diretriz o fortalecimento dos cursos públicos de Serviço

12. Disponível em: <http://www.opovo.com.br/app/fortaleza/2014/01/07/noticiafortaleza,3187141/ confira-as-notas-de-corte-desta-terca-dos-curso-do-ifce.shtml>. Acesso em: 20 abr. 2014. 
Social, há o fortalecimento dessa parceria, e isso vem se dando a partir da participação do IFCE nos GTs de trabalho e de formação profissional, a realização de alguns eventos, como a Semana do Assistente Social, que acontece em maio, além desse apoio político. (Entrevistada 6)

No que se refere à expansão do curso para outros IFs, as representações do Cress e da Abepss especialmente consideram importante tal iniciativa, apontando para a necessidade de garantir mais cursos públicos, já que historicamente é uma bandeira de luta das entidades. Porém há também ponderações no que diz respeito a esse processo, considerando, por vezes, ideal a abertura em universidades e o fortalecimento do curso já existente no IFCE para que este sirva como "projeto-piloto".

Não temos uma posição formal da Abepss em relação aos IFs, o que essa pesquisa nos chama a fazê-lo. Enquanto significar o avanço do ensino superior, público e presencial, devemos apoiar, especialmente por adensar [...] uma alternativa à expansão da mercantilização da educação e do EaD. (Entrevistada 8)

As entidades, em sua maioria, demonstram desconhecimento do projeto de formação e das diretrizes que orientam o curso no IFCE, não possuindo, portanto, ações concretas para a proposta de expansão, mas somente perspectiva de planejamento para pautar em reuniões futuras. Essa realidade, no entanto, vem tomando novos contornos. Sobre isso, segundo o Relatório Final do $42^{\circ}$ Encontro Nacional CFESS-Cress (2013), esfera máxima de discussão e deliberação coletiva da categoria, foi pautada a necessidade de aprofundar o debate sobre a expansão de cursos de Serviço Social em IES públicas, sendo aprovada a seguinte deliberação: "realizar estudos e debates sobre a criação de cursos de Serviço Social na Rede de Educação Profissional e Tecnológica, considerando o curso de Serviço Social do IFCE como projeto-piloto" (CFESS e Cress, 2013, p. 32). Tal fato, somado aos demais aspectos que já brevemente apresentamos, demanda maior empenho dos trabalhadores da educação e estudantes, em constante articulação com as organizações políticas e profissionais, na consolidação de iniciativas e construção de bandeiras unitárias que efetivamente represente uma entre tantas outras conquistas no âmbito da formação profissional, em particular no Serviço Social. 


\section{Considerações finais}

A aproximação da realidade e das suas diversas dimensões nos ensina que, no movimento complexo e dinâmico que constitui a sociedade contemporânea, o "pessimismo fatalista" e o "otimismo vazio de concretude" dificultam alçarmos passos mais largos no enfrentamento à mercantilização da vida social, particularmente no âmbito da educação, que venham a ampliar o direito a uma formação profissional pública, gratuita e de qualidade. Tal concepção acompanhou a trajetória da nossa pesquisa, entendendo que, apesar dos limites e percalços, há um caminho aberto para possibilidades que a história nos possa apresentar.

Chamamos novamente a atenção ao fato de o curso de Serviço Social do IFCE ainda representar uma experiência recente, o que nos impede de termos maiores subsídios que viabilizem uma análise mais aprofundada sobre seus reflexos na formação de assistentes sociais no estado e nas políticas públicas em âmbito regional. Entretanto, a realidade da graduação, como podemos observar, apesar de inédita, não é simples. Envolve um conjunto de mediações que exigem de nós extrapolar a esfera local, o imediatismo, e compreender o que está em jogo no projeto de desenvolvimento em curso.

A profissão, em matéria de formação profissional, vivencia os reflexos de um complexo e contraditório pêndulo entre o acesso e a precarização, característico do "neodesenvolvimentismo", partícipe da trajetória de um país de capitalismo periférico e dependente em meio às transformações contemporâneas notadamente atravessadas pela financeirização da economia e reestruturação produtiva. Os reflexos desse processo logo se apresentam para a profissão como solo propício, de um lado, para a atualização do conservadorismo, a exemplo do aligeiramento dos conteúdos e do rebaixamento acadêmico, que tendencialmente implica um perfil profissional mais pragmático, acrítico e assistencialista; de outro, para condições renovadas do ponto de vista da luta política que incidam sob as contradições do contexto atual e viabilizem conquistas no âmbito da educação pública, entre outras.

No seio dessa conjuntura nasce o bacharelado em Serviço Social no IFCE. A princípio, poderíamos conceber esse aspecto somente como uma demanda 
do capital, uma forma de precarizar a educação superior, expandindo o ensino na perspectiva técnica e tecnológica, a baixo custo, sem a garantia do tripé ensino, pesquisa e extensão, frente às novas configurações do mercado de trabalho. A partir daí, assegurar que esse processo contribui para um rebaixamento da formação profissional, tendo em vista que a experiência universitária foi fundamental para a "intenção de ruptura" (Netto, 2011) e que a expansão do curso de Serviço Social pelos IFs é simplesmente uma ameaça, um retorno ao tecnicismo e a outras formas renovadas do conservadorismo, tão presente na gênese da profissão. Entretanto, apenas chegarmos a tais afirmações não nos basta, simplesmente porque, a nosso ver, não dá conta do movimento do real, histórico, dinâmico e contraditório, constituído não apenas por determinantes e circunstâncias no âmbito econômico, como também por aspectos no plano da política, da "relação de forças sociais" (Gramsci, 2007).

É preciso entender, portanto, que a realidade dos IFs, e particularmente do curso de Serviço Social, não é isolada e engessada, mas relacionada à dinâmica de crescimento exponencial de formas de ensino extremamente precarizadas, ao histórico déficit educacional e à desigualdade regional, às mudanças ocorridas na última década no Brasil e na própria "natureza" dos IFs etc. Todo esse processo vem viabilizando, portanto, no seio das adversidades encontradas hoje no âmbito da educação superior que, inclusive, extrapolam a realidades dos IFs, a implementação do curso em questão respaldado nas Diretrizes Curriculares da Abepss e no Projeto Ético-político Profissional, levando em consideração as particularidades regionais e institucionais. A graduação em questão vem se referenciando no estado em meio à proliferação de cursos - em geral sem qualquer parâmetro de qualidade - , de cursos por intermédio de instituições privadas e/ou de caráter filantrópico.

Não obstante, desde sua criação, o curso em questão vem enfrentando dificuldades e apresentando potenciais que se configuram como verdadeiros desafios. Dentre esses podemos situar a "cultura institucional", que, mesmo com reconfigurações mais recentes, não possui tradição em cursos das áreas das Ciências Humanas e Sociais. A condição de professor de EBTT, em vez da carreira de magistério superior, que demanda maior esforço coletivo para a edificação e o fortalecimento de uma formação respaldada nas Diretrizes Nacionais da ABEPSS. 
Assim como nas universidades, algumas dificuldades vêm acompanhando o curso desde sua criação até hoje, a exemplo da falta de professores e de infraestrutura necessária e adequada. Tais circunstâncias implicam também as condições de trabalho docente, que adensam os contratempos relativos a dedicação às atividades de apoio ao ensino, de pesquisa e extensão. Outros impasses revelam a necessidade de adequar o curso à reformulação do PPC, viabilizando a integralização curricular, bem como a demanda por demais condições previstas na Política de Estágio Supervisionado Curricular em Serviço Social (IFCE, 2013).

Contudo, é importante observar que o processo de interiorização das instituições e dos cursos públicos representa também a possibilidade de incidir sob a dinâmica local e regional, especialmente no âmbito das políticas sociais, através de ações no âmbito do estágio supervisionado (Fóruns de Supervisores de Estágio, Capacitações para Supervisores etc.), bem como da extensão, pesquisa e dos fluxos migratórios, viabilizando o acesso a um conjunto de profissionais e estudantes que passam a demandar melhorias no âmbito da política de assistência estudantil, das condições de trabalho docente, entre outras.

Outro aspecto a ser considerado nesse processo é a condição pública e federal da instituição, que vem possibilitando espaços de debates e de articulação direta com as organizações da profissão, de formação crítica que concebe educação como direito, que viabiliza a atração de docentes concursados e qualificados para o interior do estado.

Portanto, estamos diante do desafio que nos acompanha cotidianamente frente ao atual quadro de expansão da educação superior: formar profissionais competentes, críticos e comprometidos, com capacidade teórico-metodológica, ético-política e técnico-operativa. Isso, no entanto, só é possível a partir de uma leitura aprofundada da realidade e da profissão, dos seus fundamentos, articulada à capacidade de instrumentalizá-la, a partir também do conhecimento e da habilidade operativa e instrumental no âmbito das políticas sociais. Caso contrário, serão reforçados equívocos históricos, a exemplo do tecnicismo/pragmatismo e do teoricismo/academicismo.

Assim, o fortalecimento político-organizativo dos profissionais e estudantes junto à ampliação da esfera pública é fundamental, sendo o curso de Serviço 
Social do IFCE uma importante experiência que, sem dúvida, contribuirá para ampliar nossas reflexões e ações na construção de estratégias coletivas de enfrentamento à precarização e ao conservadorismo que venham a garantir conquistas concretas não apenas para o Serviço Social, mas para o conjunto da classe trabalhadora.

Recebido em: 14/8/2014 - Aprovado em: 10/3/2015

\section{Referências bibliográficas}

ABEPSS. Associação Brasileira de Ensino e Pesquisa em Serviço Social. Relatório final da pesquisa avaliativa da implementação das diretrizes curriculares do curso de Serviço Social. São Luís, 2008. Disponível em: <http://pt.scribd.com/doc/170327020/ relatoriofinal-ABEPSS-1>. Acesso em: 2 maio 2013.

ABEPSS. Diretrizes gerais para o curso de Serviço Social. Rio de Janeiro: Abepss, 1996.

ALVES, Giovanni. Precariado: a espinha dorsal dos protestos nas ruas das 353 cidades brasileiras. 2013. Disponível em: $<$ http://www.ihu.unisinos.br/entrevistas/521567 a-insatisfacao-social-acumulada-entrevista-especial-com-giovanni-alves $>$. Acesso em: 23 ago. 2013.

ANTUNES, R. A nova morfologia do trabalho e o desenho multifacetado das ações coletivas. In RAMALHO, José Ricardo; SANTANA, Marco Aurélio (Orgs.). Além da fábrica: trabalhadores, sindicatos e a nova questão social. São Paulo: Boitempo, 2003.

BEHRING, E. Brasil em contrarreforma: desestruturação do Estado e perda de direitos. 2. ed. São Paulo: Cortez, 2008.

BOITO JR., A. As bases políticas do neodesenvolvimentismo. 2012. Disponível em: $<$ http://eesp.fgv.br/sites/eesp.fgv.br/files/file/Painel\%203\%20-\%20Novo\%20Desenv\%20BR \%20-\%20Boito\%20-\%20Bases\%20Pol\%20Neodesenv\%20-\%20PAPER. pdf $>$. Acesso em: 20 maio 2013.

BRAGA, R. A política do precariado: do populismo à hegemonia lulista. São Paulo: Boitempo, 2012. 
BRASIL. Lei n. 8.662. Dispõe sobre a profissão de assistente social e dá outras providências. Brasília, 7 jun. 1993.

. Lei n. 11.892. Institui a Rede Federal de Educação Profissional, Científica e Tecnológica, cria os Institutos Federais de Educação, Ciência e Tecnologia, e dá outras providências. Brasília, 29 dez. 2008.

. Ministério da Educação (MEC). Expansão da Educação Superior e Tecnológica e Profissional, 2013. Disponível em: $<$ http://portal.mec.gov.br/expansao/>. Acesso em: 23 jun. 2013.

. Ministério da Educação (MEC). Painel de Controle do MEC, 2014. Disponível em: <http://painel.mec.gov.br/>. Acesso em: 23 fev. 2014.

CFESS/CRESS. Relatório Final do $42^{\circ}$ Encontro Nacional CFESS-CRESS. Recife, 2013. Disponível em: < www.cfess.org.br/arquivos/relatorio-nacional-2013-pdf $>$. Acesso em: 7 fev. 2014.

CONSELHO REGIONAL DE SERVIÇO SOCIAL (CRESS). Boletim do CRESS $3^{a}$ Região. Fortaleza, 2014. Disponível em: <http://www.calameo.com/read/001289987 fe72d3ab8fc1>. Acesso em: 16 maio 2014.

DAHMER, L. Mercantilização do ensino superior, educação à distância e Serviço Social. Temporalis. Brasília, ano 8, n. 15, p. 35-52, 2008.

FERNANDES, Florestan. A revolução burguesa no Brasil: ensaio de interpretação sociológica, 5. ed. São Paulo: Globo, 2006.

GENTILI, P.; OLIVEIRA, D. A. A procura da igualdade: dez anos de política educacional no Brasil. In: SADER, Emir (Org.). 10 anos de governos pós-neoliberais no Brasil: Lula e Dilma. São Paulo: Boitempo; Rio de Janeiro: Flacso Brasil, 2013.

GRAMSCI, A. Cadernos do cárcere. 3. ed. Rio de Janeiro: Civilização Brasileira, 2007. v. 3.

HARVEY, D. Condição pós-moderna. 19. ed. São Paulo: Loyola, 2010.

IAMAMOTO, M. V. O Serviço Social na contemporaneidade: trabalho e formação profissional. 7. ed. São Paulo: Cortez, 2004.

. Serviço Social em tempo de capital fetiche: capital financeiro, trabalho e questão social. São Paulo: Cortez, 2007.

Serviço Social na cena contemporânea. In: . Serviço Social: direitos sociais e competências profissionais. Brasília: CFESS/Abepss, 2009. 
IANNI, Octavio. Pensamento social no Brasil. São Paulo: EDUSC, 2004.

INSTITUTO FEDERAL DE EDUCAÇÃO, CIÊNCIA E TECNOLOGIA DO CEARÁ (IFCE). Estatuto do Instituto Federal do Ceará. 2008. Disponível em: <www.cefetce. br/images/stories/Acesso_a_Informação/ESATATUTO_FINAL-PUBLICADO_NO_ DIARIO_OFICIAL-20-08-2009.PDF>. Acesso em: 20 maio 2013.

. Câmpus Iguatu. Projeto Político-Pedagógico do Curso de Serviço Social, 2013.

INSTITUTO NACIONAL DE ESTUDOS E PESQUISAS EDUCACIONAIS ANÍSIO TEIXEIRA(INEP). Censo da Educação Superior, 2010. Disponível em: <http://portal. inep.gov.br/web/censo-da-educacao-superior>. Acesso em: 12 ago. 2013.

LIMA, K. Contrarreforma da educação superior e formação profissional em Serviço Social. Temporalis, Brasília, ano 8, n. 15, p. 17-34, 2008.

MONTAÑO, C. A natureza do Serviço Social: um ensaio sobre sua gênese, a "especificidade" e sua reprodução. 2. ed. São Paulo: Cortez, 2009.

MOTA, A. E. Cultura da crise e seguridade social: um estudo sobre as tendências da previdência e da assistência social brasileira nos anos 80 e 90. São Paulo: Cortez, 1995.

NETTO, J. P. Ditadura e Serviço Social, 16. ed. São Paulo: Cortez, 2011.

ORTIZ, F. G. O Serviço Social no Brasil: os fundamentos de sua imagem social e da autoimagem de seus agentes. Rio de Janeiro: E-papers, 2010. 